\title{
RANCANG BANGUN ALAT PENGKONVERSI SAMPAH PLASTIK MENGGUNAKAN METODE PIROLISIS MENJADI BAHAN BAKAR MINYAK DALAM UPAYA PENANGANAN MASALAH LINGKUNGAN
}

\author{
DEWI AMALIA ARDIANTI, ALDY AMIRUDDIN NAJIB, FAISAL NUR HAKIM, UHTI \\ SETIORINI, SRI SURYANINGSIH* \\ Departemen Fisika Fakultas MIPA Universitas Padjadjaran, \\ Jl. Raya Bandung-Sumedang Km 21,Jatinangor 45363 \\ *email : sri@phys.unpad.ac.id
}

\begin{abstract}
Abstrak. Limbah plastik masih menjadi salah satu permasalahan utama pada lingkungan di dunia, termasuk Indonesia. Salah satu alternatif penanganan limbah plastik adalah dengan mengkonversi limbah plastik menjadi bahan bakar minyak dengan metode pirolisis. Pirolisis adalah proses dekomposisi suatu bahan pada temperatur tinggi tanpa adanya oksigen. Pada penelitian ini, dilakukan proses pirolisis pada limbah plastik HDPE dengan reaktor berbahan stainless steel yang telah dirancang untuk menghasilkan bahan bakar minyak, sebesar $460 \mathrm{ml}$ dan 1846,5 ml minyak dan dengan variasi temperatur kondensasi $26^{\circ} \mathrm{C}$ dan $17^{\circ} \mathrm{C}$. Proses pirolisis limbah plastik dilakukan pada temperatur rata-rata pemanasan $606,9^{\circ} \mathrm{C}$ dan $640,6^{\circ} \mathrm{C}$. Sehingga, menghasilkan efisiensi dari reaktor $27,93 \%$ untuk temperatur kondensasi $26^{\circ} \mathrm{C}$ dan $66,34 \%$ untuk temperatur kondensasi $17^{\circ} \mathrm{C}$. Berdasarkan perbandingan karakteristik bahan bakar minyak hasil pirolisis dengan standar bahan bakar solar (SNI 06-4131-1996) dijelaskan bahwa bahan bakar minyak yang dihasilkan mendekati dengan spesifikasi SNI. Karakteristik bahan bakar meliputi, indeks setana, yaitu 53,9, kandungan sulfur, sebesar 0,05\%wt, dan nilai kalor yang tinggi, yaitu $11,179 \mathrm{kkal} / \mathrm{kg}$ yang menunjukkan kualitas yang baik dari pemanasan bahan bakar. Namun, viskositas sebesar $1,188 \mathrm{~mm}^{2} / \mathrm{s}$, berat jenis sebesar $777,2 \mathrm{~kg} / \mathrm{m}^{3}$, dan flash point di bawah $-5^{\circ} \mathrm{C}$ menunjukkan pelumasan dan regulasi keamanan yang kurang baik jika digunakan pada mesin.
\end{abstract}

Kata kunci: Limbah Plastik HDPE, Pirolisis, Bahan Bakar Solar

\begin{abstract}
Plastic waste has become a major environmental problem all over the world, including Indonesia. The problem is caused by the production and use of plastic waste that is not balanced with the waste management. One alternative handling of plastic waste is to convert plastic waste into fuel oil by pyrolysis method. Pyrolysis is a decomposition process of material at high temperatures in the absence of oxygen. In this research, HDPE waste plastic was pyrolyzed in a self-designed stainless-steel reactor to produce fuel products $460 \mathrm{ml}$ and $1846,5 \mathrm{ml}$, using variation of condensation temperature $26^{\circ} \mathrm{C}$ and $17^{\circ} \mathrm{C}$. HDPE waste plastic was completely pyrolyzed at average $606,9^{\circ} \mathrm{C}$ and $640,6^{\circ} \mathrm{C}$ for 150-240 minutes. In a result, it obtained the efficiency of reactor, $27,93 \%$ at condensation temperature of $26^{\circ} \mathrm{C} \mathrm{kg}$ and $66,34 \%$ at condensation temperature of $17^{\circ} \mathrm{C}$. Comparison of fuel pyrolysis oil properties to diesel fuel Indonesian National standards (SNI 06-41311996) revealed that the fuel oil product was almost close to SNI specification. The fuel properties included calculate cetane index of 53,9, Sulphur content of 0,05 (\%wt), and high calorific value of $11,179 \mathrm{kcal} / \mathrm{kg}$ that represented quality of fuel combustion. However, viscosity of $1,188 \mathrm{~mm}^{2} / \mathrm{s}$, density of $777,2 \mathrm{~kg} / \mathrm{m}^{3}$, and flash point below $-5^{\circ} \mathrm{C}$ showed that lubrication and safety regulation is not good enough when it is used in machine.
\end{abstract}

Keywords: HDPE Waste Plastic, Pyrolysis, Diesel Fuel Oil 


\section{Pendahuluan}

Plastik adalah salah satu bahan yang sering ditemui di hampir setiap barang rumah tangga, seperti botol minum, lotion, sabun dan sampo, alat makan, kantong pembungkus, pipa, sikat gigi, botol oli, dan lain-lain. Hal tersebut dikarenakan plastik merupakan produk serbaguna, ringan, fleksibel, tahan kelembaman, kuat, dan relatif murah. Dengan berbagai kemudahan tersebut, semakin banyak produk plastik yang dihasilkan dan digunakan di berbagai Negara, salah satunya Indonesia. Menurut Kemenperin (2013), Indonesia tercatat sebagai Negara pengguna plastik kedua terbesar di dunia dengan konsumsi yang diproyeksikan mencapai 1,9 juta ton hingga semester I-2013 yang kemudian meningkat sekitar 22,58\% pada semester yang sama tahun lalu sebanyak 1,55 juta ton $[1,2]$. Konsumsi plastik yang besar ini dapat menghasilkan limbah plastik, yang apabila tidak dilakukan pengelolaan yang seimbang dengan produksi dan penggunaan plastik, maka akan menumpuk dan menjadi sampah. Sampah plastik yang menumpuk dapat menyebabkan permasalahan lingkungan mapupun kesehatan, karena plastik bersifat nonbiodegredable (sulit terdegradasi) oleh lingkungan.

Mengingat limbah plastik banyak dihasilkan di lingkungan domestik dan dinilai sebagai masalah yang paling dekat dengan kehidupan manusia, di mana hampir setiap aktivitas manusia berada dalam lingkungan rumah tangga (domestik) yang berpeluang menghasilkan limbah-limbah baru setiap harinya. Dengan produksi limbah plastik yang dapat dikatakan cukup besar, maka perlu dilakukannya pengolahan limbah tersebut. Proses pengolahan yang dapat dilakukan yaitu, dengan proses termokimia. Proses termokimia yang dapat dilakukan, yaitu pirolisis dengan mengubah limbah plastik menjadi bahan bakar cair alternatif $[3,4]$.

Melalui proses pirolisis, dapat diterapkannya dalam pengolahan limbah plastik berjenis HDPE pada reaktor pirolisis, di mana sampah plastik HDPE sendiri memiliki nilai kalor yang cukup besar, yaitu $14.246 \mathrm{~kJ} / \mathrm{kg}[5,6]$ yang berpotensi dapat dijadikan solusi permasalahan limbah plastik yang ada dan sumber bahan bakar alternatif berupa minyak pengganti fosil di mana karakteristiknya akan diteliti kesesuaiannya dengan bahan bakar minyak solar sehingga dapat dimanfaatkan menjadi bahan bakar minyak komersial di kemudian hari. Untuk mengatasi permasalah yang ada di buatlah alternatif yaitu rancang bangun reaktor pirolisis yang memanfaatkan limbah plastik menjadi bahan bakar minyak.

\section{Metode Penelitian}

Rancang bangun dari reaktor pirolisis yang akan digunakan diperlihatkan pada Gambar 1.

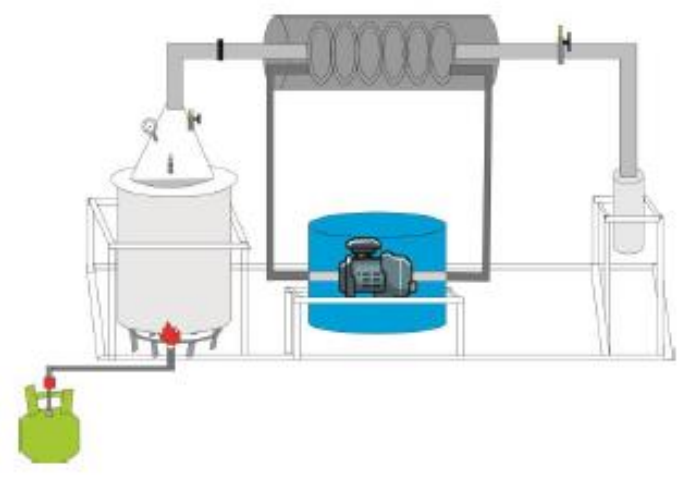

Gambar 1. Skema reaktor pirolisis 
Bagian-bagian pada reaktor pirolisis : tabung pemanasan (menggunakan bahan stainless steel dengan diameter $20 \mathrm{~cm}$ dan tinggi $30 \mathrm{~cm}$ yang mampu menahan tekanan kerja 2-3 bar, dan dilengkapi prison gate, pressure gauge, dan safety valve untuk keperluan analisa). Kondenser mmenggunakan bahan aluminium dengan panjang $30 \mathrm{~cm}$ dan diameter $15 \mathrm{~cm}$. Reservoar air menggunakan box container kapasitas $50 \mathrm{~L}$, pompa, dan selang air.

Pada tahap pembuatan minyak pirolisis, diawali dengan pemilahan limbah plastik HDPE, kemudian mencacah limbah plastik HDPE dengan mesin perajang plastik menjadi ukuran yang lebih kecil. Lalu mencuci dan mengeringkan limbah plastik HDPE yang terlah dicacah. Hal ini dapat dilihat pada Gambar 2.

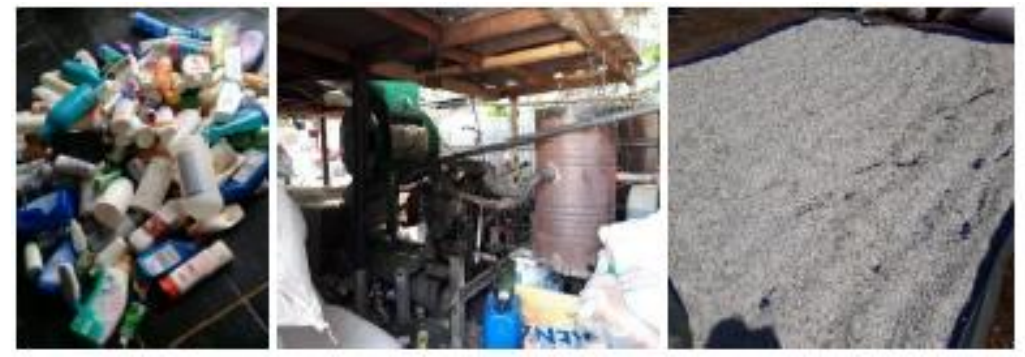

Gambar 2. (a) Pengumpulan limbah plastik HDPE. (b) Penggilingan dan pencucian limbah plastik HDPE. (c) Pengeringan limbah plastik HDPE yang telah dicacah

Proses pembuatan minyak pirolisis ini melalui proses pirolisis dengan variasi temperatur kondensasi, yaitu $26^{\circ} \mathrm{C}$ dan $17^{\circ} \mathrm{C}$. Pada variasi pertama menggunakan temperatur pemanasan berkisar $563,6^{\circ} \mathrm{C}$ hingga $703,4^{\circ} \mathrm{C}$, dan pada variasi kedua menggunakan temperatur pemanasan berkisar $587,5^{\circ} \mathrm{C}$ hingga $726,2^{\circ} \mathrm{C}$, yang kemudian akan dibandingkan lamanya waktu dan temperatur pemanasan terhadap kapasitas minyak pirolisis limbah plastik yang dihasilkan. Limbah plastik HDPE yang sudah tercacah dan kering ini dimasukkan pada tabung reaktor pirolisis, di mana akan mengalami proses pemanasan dengan menyalakan burner yang bahan bakarnya berasal dari gas LPG $3 \mathrm{~kg}$, di mana terjadi perubahan wujud dari padat ke gas (menyublim). Dengan menyalakan pompa air, sehingga dapat memompakan air dari container yang berisikan air ke kondenser sebagai pendingin pada tabung reaktor, yang disebut proses liquification, di mana merupakan proses perubahan wujud dari gas ke cair dengan proses kondensasi (pendinginan). Pada tahap liquification ini dilakukan destilasi atau penyulingan pada kondenser agar menghasilkan minyak pirolisis yang lebih jernih. Kemudian akan dihasilkan minyak pirolisis berupa asap cair yang dapat ditampung dalam gelas ukur.

Tahap pengujian, meliputi uji nilai viskositas, densitas, nilai kalor, flash point, kandungan sulfur, dan angka setana, perhitungan efisiensi reaktor pirolisis. Cetane index atau indeks setana merupakan kualitas penyalaan dalam bahan bakar solar yang berhubungan dengan kelambatan penyalaan yang bergantung pada komposisi bahan bakar. Angka setana yang tinggi menggambarkan autoignition (Kemampuan bahan bakar menyala dengan sendirinya) yang cepat dari bahan bakar motor diesel/ minyak Solar. Batasan minimal Cetane Number solar adalah 48.

Viskositas kinematik adalah pengukuran berdasarkan aliran fluida cair yang mengalir dengan volume tetap dengan aliran gravitasi melewati viscometer kapiler. 
Viskositas sangat menentukan dalam pengkabutan. Viskositas yang terlalu rendah dapat mengakibatkan kebocoran pada pompa injeksi bahan bakar, sedangkan viskositas yang terlalu tinggi dapat mempengaruhi kerja cepat alat injeksi bahan bakar dan mempersulit pengabutan bahan bakar minyak.

\section{Hasil dan Pembahasan}

Pada penelitian untuk membuat bahan bakar minyak dari limbah plastik HDPE diawali dengan perancangan reaktor pirolisis. Reaktor pirolisis ini berbahan dasar stainless steel , yang terdiri dari tiga komponen utama, yaitu tabung pemanasan, tabung destilasi, dan kondenser, seperti pada Gambar 3.

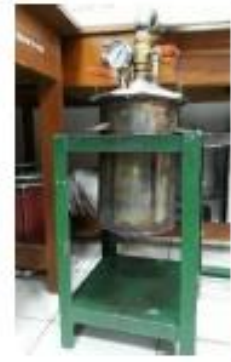

(a)

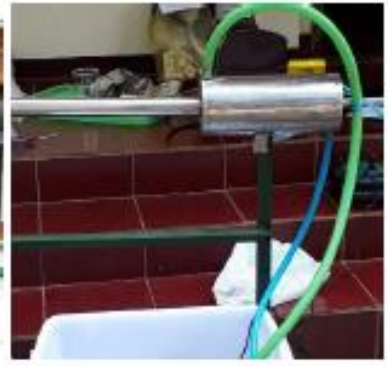

(b)

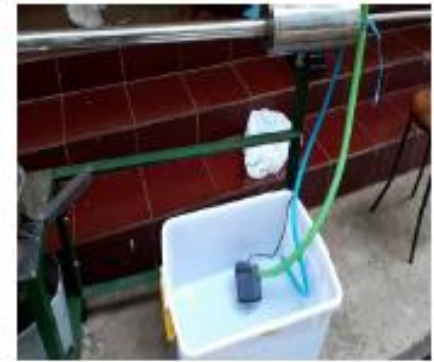

(c)

Gambar 3. (a) Komponen reaktor pirolisis. (a) Tabung pemanasan. (b) Kondenser.

(c) Reservoar air

Komponen pertama pada reaktor pirolisis, yaitu tabung pemanasan yang dilengkapi dengan prison gate, pressure gauge, dan safety valve dan terdiri dari pipa penghubung dengan panjang $86 \mathrm{~cm}$ di mana berfungsi sebagai konektor dengan tabung destilasi.

Dari hasil percobaan pertama digunakan temperatur kondensasi $26^{\circ}$ dihasilkan minyak sebesar $3195 \mathrm{ml}$ dalam waktu 129 menit dengan waktu penyulingan awal pada menit ke 21 pada temperatur yang diberikan kompor, yaitu $630,9^{\circ} \mathrm{C}$. Sedangkan pada percobaan kedua digunakan temperatur kondensasi $17^{\circ} \mathrm{C}$ dihasilkan minyak sebesar $2115 \mathrm{ml}$ dalam waktu 210 menit dengan waktu penyulingan awal pada menit ke 30 dengan temperatur yang diberikan kompor, yaitu $606,2^{\circ} \mathrm{C}$. Perbedaan waktu pemanasan dari setiap variasi temperatur kondensasi pada percobaan dikarenakan pada percobaan pertama, di mana waktu pemanasan lebih cepat dari percobaan kedua, temperatur pada tabung pemanasan semakin tinggi yang tidak diimbangi temperatur pendinginan (kondenser) sehingga menyebabkan temperatur minyak yang dihasilkan sangat tinggi dan pada menit ke 150 menit sudah tidak dilakukan pemanasan lagi. Sedangkan pada percobaan kedua yang dapat melakukan proses pemanasan lebih lama, dibandingkan percobaan pertama dan kedua dikarenakan telah diperoleh temperatur kondensasi optimal pada saat pemanasan. 
Tabel 1. Perbandingan Karakteristik Minyak Pirolisis Limbah Plastik dengan Literatur SNI Solar/Biosolar [7]

\begin{tabular}{|c|c|c|c|c|c|c|}
\hline \multirow[t]{3}{*}{ Karakteristik } & \multirow[t]{3}{*}{ Satuan } & \multirow{3}{*}{$\begin{array}{l}\text { Minyak } \\
\text { Pirolisis } \\
\text { Limbah } \\
\text { Plastik } \\
\text { HDPE }\end{array}$} & \multicolumn{3}{|c|}{ Solar/Biosolar SNI } & \multirow{3}{*}{$\begin{array}{c}\text { Metode } \\
\text { Uji } \\
\text { ASTM }\end{array}$} \\
\hline & & & \multicolumn{3}{|c|}{ Batasan } & \\
\hline & & & Solar 48 & Solar 51 & Solar 53 & \\
\hline Indeks Setana & & 53,9 & $\geq 45$ & $\geq 48$ & $\geq 50$ & D 4737 \\
\hline $\begin{array}{c}\text { Berat Jenis @ } \\
15^{\circ} \mathrm{C}\end{array}$ & $\mathrm{kg} / \mathrm{m}^{3}$ & 777,2 & $815-860$ & $820-860$ & $820-850$ & D 4052 \\
\hline $\begin{array}{c}\text { Viskositas@ } \\
40^{\circ} \mathrm{C}\end{array}$ & $\mathrm{mm}^{2} / \mathrm{s}$ & 1,188 & $2,0-4,5$ & $2,0-4,5$ & $2,0-4,0$ & D 445 \\
\hline Flash Point & ${ }^{\circ} \mathrm{C}$ & $\begin{array}{c}\text { Di } \\
\text { bawah }-5\end{array}$ & $\geq 55$ & $\geq 55$ & $\geq 55$ & D93 \\
\hline $\begin{array}{c}\text { Kandungan } \\
\text { Sulfur }\end{array}$ & \%wt & 0,050 & $\leq 0,05$ & $\leq 0,05$ & $\leq 0,05$ & D 4294 \\
\hline $\begin{array}{c}\text { Nilai Kalor } \\
\text { (BTU/lb) }\end{array}$ & Kkal/kg & 11.179 & & $\geq 10.879$ & & D 240 \\
\hline
\end{tabular}

Berdasarkan Tabel 1, apabila ditinjau dari karakteristik keseluruhan yang dihasilkan, diperoleh hasil spesifikasi yang belum sesuai dengan bahan bakar solar/biosolar, karena flash point yang terlalu rendah dapat berbahaya jika digunakan dalam mesin dan penyimpanan sedangkan nilai viskositas dan densitas yang terlalu rendah dapat menyebabkan gesekan (abrasive) dalam ruang bakar sehingga mengakibatkan pelumasan yang kurang baik. Namun jika ditinjau dalam pembakaran, hasil pengujian bahan bakar minyak pirolisis ini sudah sesuai, dikarenakan selain memiliki angka setana, nilai kalor, dan kandungan sulfur yang baik, nilai viskositas, densitas, dan flash point yang rendah ini memungkinkan untuk pembakaran yang cepat pada mesin. Hanya perlu dilakukan pengaturan temperatur yang sesuai dalam penyimpanan bahan bakar hasil pirolisis limbah plastik HDPE.

\section{Kesimpulan}

Telah dihasilkan rancangan reaktor pirolisis yang terdiri dari tiga komponen utama, yakni tabung pemanasan dengan diameter $20 \mathrm{~cm}$, tinggi $30 \mathrm{~cm}$, dan kapasitas maksimum $4 \mathrm{~kg}$, kondenser dengan panjang $30 \mathrm{~cm}$ dan diameter $15 \mathrm{~cm}$, serta reservoar air dengan kapasitas $50 \mathrm{~L}$ sebagai sumber pendingin pada kondenser.

Dengan menggunakan reactor pirolisis tersebut dihasilkan bahan bakar minyak limbah plastik HDPE sebanyak $460 \mathrm{ml}$ minyak dengan temperatur pemanasan $606,9^{\circ} \mathrm{C}$ dan kondensasi $26^{\circ} \mathrm{C}$ serta $1846,5 \mathrm{ml}$ minyak dengan temperatur pemanasan $640,6^{\circ} \mathrm{C}$ dan kondensasi $17^{\circ} \mathrm{C}$, di mana semakin besar temperatur pemanasan dan rendahnya temperatur kondensasi maka kapasitas minyak yang dihasilkanpun akan semakin besar. 


\section{Daftar Pustaka}

1. Agrariksa, A. Fintas et al. Uji Performansi Motor Bakar bensin (On Chassis) Menggunakan Campuran Premium dan Etanol. Jurnal Keteknikan Pertanian Tropis dan Biosistem Vol. 1 No. 03 (2013) 194-203.

2. B. Aydinli and A. Caglar, The Comparison of Hazelnut Shell Co-Pyrolysis with Polyethylene Oxide and Previous Ultra-High Molecular Weight Polyethylene. Journal of Analytical and Applied Pyrolysis. 87 (2010) 263-268.

3. P. Bhattacharya, P. Steele, E.B.M. Hassan, B. Mitchell, L. Ingram, C.U. Pittman, 2009. Wood/Plastic co-Pyrolysis in an Auger Reactor : Chemical and Physical Analysis of The Products. Fuel. 88 (2009) 1251-1260.

4. BPPT. 2017. Nilai Kalor Menentukan Harga Batu Bara. http://btbrd.bppt.go.id/index.php/28-articles/197-nilai-kalor-menentukanharga-batubara (Akses: 16 Desember 2017).

5. O.H. Cahyonugroho, Pengaruh Intensitas Sinar Ultraviolet dan Pengadukan Terhadap Reduksi Jumlah Bakteri E.coli. Jurnal Ilmiah Teknik Lingkungan Vol. 2 No. 1 (2002) 18-22.

6. Daniel. 2016. Solar Hitam atau Industrial Diesel Oil. https://danielpetrawaas.files.wordpress.com/2016/05/gasoil-diesel-oil.ppt (Akses: 15 Desember 2017).

7. Departemen Energi dan Sumber Daya Mineral Republik Indonesia. 2006. Keputusan Direktur Jenderal Minyak dan Gas Bumi Nomor 8757.J/24/DJM/2006. Tata Cara Pengawasan, Bahan Bakar Minyak, Bahan Bakar Gas, LPG, Hasil Olahan, dan Bahan Bakar lain. Direktur Jenderal Minyak dan Gas Bumi : Jakarta. 